\title{
Proximate, elemental and thermo gravimetric analyses of bangladeshi coal
}

\begin{abstract}
Within the next decade coal will be the main energy source of Bangladesh. It is assumed that, other fossil fuels like natural gas and oil stocks will be exhausted within 10 to 15 years and a viable alternate energy option is yet to find. This research was done to determine the proximate, elemental and thermo gravimetric analysis of Bangladeshi coal and to compare these results with the Indonesian coal. The higher calorific values from proximate analysis indicate excellent combustibility of local coal samples. The proximate analysis also reveals the sulfur content is low in Bangladeshi coal samples than the Indonesian one. Elemental analysis of the local coal samples indicates relatively low amount of toxic trace elements comparing to Indonesian coal.
\end{abstract}

Volume 2 Issue 4 - 2017

\author{
Md Ashraful Abedin, Tajkia Jannat, Nusrat \\ Fatema Nayan, Md lqbal Hossain \\ Department of Chemical Engineering, Bangladesh University of \\ Engineering and Technology, Bangladesh
}

Correspondence: Md lqbal Hossain, Department of Chemical Engineering, Bangladesh University of Engineering and Technology, Bangladesh, Email iqbalhossain@che.buet.ac.bd

Received: March 27, 2017 | Published: May 26, 2017

\section{Introduction}

The naturally occurring combustible material -Coal, primarily consists of the elemental carbon along with low percentages of solid, liquid and gaseous hydrocarbons and/or other materials, such as compounds of nitrogen and sulfur. Coal, the most available fossil fuel used to generate almost half of the world's total electricity. It can be used efficiently in Bangladesh to generate electricity in thermal power plants to meet the increasing demand.

As a source of energy, quality and efficiency of coal need to be determined. The amount of moisture, sulfur, ash, volatile matters- are the characteristics of coal from different regions that are considered while ranking. The thermal intensity is another parameter that determines the behavior of coal as it loses weight with the increase in temperature. ${ }^{2}$ Toxic trace elements released with the combustion of coal have detrimental effect on human, animal and plant lives. The release of toxic products should be controlled to provide minimal loss of the environment. Study of these features of coal is very essential, which is done thoroughly in this work using the finest coals from Barapukuria and Dighipara coal basins of Bangladesh. Later, a comparison was made with the commercial grade coal of Indonesia. ${ }^{3}$

These works were done in the initial stages of the discovery of the coal basins just to assure the quality of coals. After the proposed declaration of constructing the country's largest coal fired power plant in Rampal, these parameters are needed to be analyzed thoroughly to use Bangladeshi coals in this power plant. Coal from the very little reserve of Bangladesh has a very high calorific value and more energy efficient than natural gas and other fossil fuels that are available here. So, future research works on different aspects of the industrial uses of coals are very much necessary for Bangladesh. ${ }^{4}$

\section{Experimentation}

\section{Materials of experiment}

For this work, coal samples from three different regions were selected. The samples are-

a. Coals from Barapukuria region from the depth of 1500 feet, resourced form the Barapukuria Coal Mining Company
Limited (BCMCL), Bangladesh.

b. Two samples from Dighipara region; one from 1250 feet and the other from 1450 feet of mine depth were collected with the help of Geological Survey of Bangladesh, GSB under the government of Bangladesh.

c. Coals of commercial grades, imported by a regular Bangladeshi coal importer named (M/S/ Shah Alam Trading) from Indonesia for industrial uses of coal in the country. ${ }^{5}$

These coal samples were collected personally from the respective institutions and companies under the authorization of the department of Chemical Engineering, BUET.

\section{Methodology-proximate analysis}

\section{Calorific values}

A bomb calorimeter was used for this analysis. Weighed amount of the fuel is placed in the crucible that is supported over a ring. ${ }^{6}$ A fine copper wire touching the fuel sample is stretched across the electrodes. Oxygen supply is forced into the bomb till a pressure of $30 \mathrm{psi}$ is reached. Initial temperature of the water in the calorimeter is noted after thorough stirring. With the electricity on, the fuel in the crucible burns with the evolution of heat. The heat produced is transferred to water which is stirred throughout the experiment by the electric stirrer. ${ }^{7}$ Here 2 liters water was used. Maximum temperature shown by the thermometer is recorded. The Higher Heating Value (HHV) from temperature measured. For Lower Heating Value (LLV), calorimeter was cooled at $25^{\circ} \mathrm{C}$ and all moisture produced in bomb calorimeter was measured. Equations followed are-

$$
\begin{aligned}
& \text { For } \mathrm{HHV}=\frac{2413 \times(\mathrm{t} 2-\mathrm{t} 1)-30}{\mathrm{~W}} \mathrm{KJ} \\
& \text { For } \mathrm{LHV}=\mathrm{HHV}-\mathrm{Hv} \times \frac{\mathrm{n}(\mathrm{h} 2 \mathrm{o}) \times 12}{\mathrm{n}(\mathrm{coal}) \times 18}
\end{aligned}
$$

Final temperature of water in calorimeter $=\mathrm{t}_{2}{ }^{\circ} \mathrm{C}$

Initial temperature of water in calorimeter $=\mathrm{t}_{1}^{\circ} \mathrm{C}$

Coal Sample weight $=\mathrm{W}$ gm 


\section{Latent heat of vaporization $=\mathrm{H}_{\mathrm{v}}$}

Mole water produced in reaction $=n\left(\mathrm{H}_{2} \mathrm{O}\right)$ Mole coal used in experiment $=\mathrm{n}($ coal $)$

\section{Moisture content}

The collected samples were passed through $250 \mu \mathrm{m}$ mesh sieve. According to ASTM D3173-02, one gram sample was heated in crucible in the drying oven at $104^{\circ} \mathrm{C}$ to $110^{\circ} \mathrm{C}$ for one hour. Opening the oven, crucibles were covered, cooled in desiccators over desiccant, and weighted as soon as the capsules have reached room temperature. The percent loss in weight accounted for the moisture content and it was calculated with the formula:

Weight $\%$ Moisture, $M=\frac{\mathrm{W}_{1}-\mathrm{W}_{2}}{\mathrm{~W}_{1}} \times 100 \%$

Where,

$\mathrm{W}_{1}=$ Weight of sample taken

$\mathrm{W}_{2}=$ Weight of sample after heating

\section{Volatile matter}

The collected samples were passed through $250 \mu \mathrm{m}$ mesh sieve in Volatile Matter crucible. The silica crucible was pre-heated in muffle furnace for 1 minute at $800^{\circ} \mathrm{C}$ to remove any foreign particles. Muffle furnace was preheated around $900^{\circ} \mathrm{C}$. Then crucible with lid was placed inside the furnace. The furnace was maintained at $900^{\circ} \mathrm{C}$ and heating was carried out for exactly \& minutes. ${ }^{89}$ After that the crucible was removed, cooled in air and then in a desiccators and weighed again. The percent loss in weight gave the volatile matter content of the coal and calculation is done as per following:

$$
\begin{aligned}
& \text { Where, } \\
& \mathrm{W}_{1}=\text { Weight of the sample taken } \\
& \mathrm{W}_{2}=\text { Weight of sample after heating }
\end{aligned}
$$$$
\text { Weight } \% \text { Volatile Matter } V M=\frac{W_{1}-W_{2}}{W_{1}} \times 100 \%
$$

\section{Ash content}

Around $1 \mathrm{gm}$ of powdered coal sample was weighed and taken in an empty silica crucible. Crucible along with sample was put in muffle furnace and heated up to $700^{\circ} \mathrm{C}$ and kept 20 minutes at that temperature. ${ }^{10}$ After that crucible was removed and cooled in air and weighed. ${ }^{11}$

The calculation followed by the equation-

$$
\begin{aligned}
& \% \mathrm{ASH}=\frac{\mathbf{A}-\mathbf{B}}{\mathbf{A}} \times 100 \\
& \mathrm{~A}=\text { Weight of coal before heating } \\
& \mathrm{B}=\text { Weight of coal after heating }
\end{aligned}
$$

\section{Sulfur content - (Test Method D $20 I 5$ or D 3286)}

Sulfur was determined in the washings from the oxygen-bomb calorimeter following the calorimetric determination. The type of bomb, amount of water in the bomb, oxygen pressure, and amount of sample taken shall be the same as specified in the calorimetric determination (Test Method D 2015). The bomb did not stand in the calorimeter water for not less than 5 min after firing. Removing the bomb from the calorimeter water and open the valve carefully so as to allow the gases to escape at an approximately even rate so the pressure is reduced to atmospheric in not less than $1 \mathrm{~min} .{ }^{12}$

The bomb was opened and examined the inside for traces of unburned material or sooty deposit. All parts of the interior of the bomb was wash carefully, including the capsule, with a fine jet of water containing methyl orange (10.6) until no acid reaction is observed. It was essential to wash through the valve opening in the case of bombs equipped with compression valves, or other types of valves with large openings, as considerable spray can collect in such valve openings. ${ }^{13}$

The washings were collected in a $250-\mathrm{mL}$ beaker and titrate with standard sodium carbonate solution (10.5). $\mathrm{P}^{\mathrm{H}}$ was adjusted from 5.5 to 7.0 with dilute $\mathrm{NH}_{4} \mathrm{OH}$. The solution was heated to boiling and filtered through a qualitative paper. $250 \mathrm{ml}$ washing was heated and $10 \mathrm{ml}$ barium chloride solution was added. After boiling it was kept for precipitation for a while. Then it was filtrated and filter paper with remaining was burned at $800^{\circ} \mathrm{C}$ in muffle furnace. Weight of burnt remaining was taken as the sulfur content. ${ }^{14}$

$$
\text { Sulfur percentage } \% \mathrm{~S}=\frac{W \times 32}{233.3} \times 100
$$

Where, $\mathrm{W}=$ weight of precipitation burnt

\section{Fixed Carbon (C)}

The fixed carbon is the difference between the total weight of coal and the sum of the volatile, moisture, ash contents and sulfur contents that are in the coal sample. The fixed carbon content - Weight \% fixed Carbon $=100-(\%$ Moisture $+\%$ Volatile Matters $+\%$ Ash content $+\%$ Sulfur).

\section{Thermo gravimetric analysis (ASTM EII38)}

Around $30 \mathrm{mg}$ sample was taken for this experiment. Reactive environment established by passing $\mathrm{O}_{2}$ at a rate ranging from 10 to $100 \mathrm{~mL} / \mathrm{min}$. switching the purge gas Open the apparatus to expose the specimen holder. 11.5 Prepare the specimen was carefully placed in the specimen holder. Positioning temperature sensor the initial mass was recorded. Heating was initiated within the desired temperature range. Record the specimen mass change continuously over the temperature interval. The mass loss profile was expressed in mass percentages over temperature $25^{\circ} \mathrm{C}$ to $800^{\circ} \mathrm{C}$ ranges.

\section{Energy-dispersive $\mathrm{X}$-ray spectroscopy}

Coal sample was taken for EDS as solid form of length of $5 \mathrm{~cm}$. It was prepared as two flat sided coals to fit into the analyzer. Sample was washed with benzoic acid then it was placed in a small round plate for EDS machine and set on the EDS.

In EDS high resolution picture was taken and image was analyzed for different point areas. From the analyzing of image the trace elements in the three coal samples of Barapukuria, Dighipara and Indonesia are detected.

\section{Results \& discussion}

This work was done in order to determine the proximate analysis, amount of trace elements and response to thermal activity of Bangladeshi coals, and compared with Indonesian coal. 


\section{Proximate analysis}

The proximate analysis was done according to the ASTM certified methods. The total proximate analysis result summary is stated here in tabulated form Table 1 .

Table I Results of Proximate Analysis of Coal

\begin{tabular}{|c|c|c|c|c|c|c|c|}
\hline $\begin{array}{l}\text { Properties/ } \\
\text { coal samples }\end{array}$ & $\begin{array}{l}\text { Higher heating } \\
\text { value(Kcal/Kg) }\end{array}$ & $\begin{array}{l}\text { Lower heating } \\
\text { value(Kcal/Kg) }\end{array}$ & $\begin{array}{l}\text { Moisture } \\
\text { content(Wt \%) }\end{array}$ & $\begin{array}{l}\text { Volatile } \\
\text { matter(Wt \%) }\end{array}$ & $\begin{array}{l}\text { Ash } \\
\text { content(Wt } \\
\%)\end{array}$ & $\begin{array}{l}\text { Sulfur } \\
\text { content(Wt } \\
\%)\end{array}$ & $\begin{array}{l}\text { Fixed } \\
\text { carbon(Wt } \\
\%)\end{array}$ \\
\hline Barapukuria & 6963.81 & 6780.41 & 6.66 & 33 & 11.93 & $0.4 I$ & 48 \\
\hline Dighipara & 6121.24 & 5932.64 & 2.78 & 36.06 & 13.69 & 0.52 & 46.95 \\
\hline Indonesia & 5704.45 & 5516.015 & 6.11 & 44.47 & 10.18 & 1.67 & 37.57 \\
\hline
\end{tabular}

The table indicates that the HHV of Bangladeshi coals is far better than the Indonesian coals, which means the heating efficiency of coals of this region is better than the Indonesian commercial grade coals. Lower heating value also shows the high quality of Bangladeshi coal samples over Indonesian coal. The ash content shows the quality of coal as a combustible fuel. Ash analysis shows that the coal of Barapukuria has ash content close to that of the commercial graded Indonesian coal. This makes the coal of this region easy for industrial use, as in case of the power plants. The lower the ash content, the better it is for the environment because combustion residue will remain in air or dispose in land. That's why the coals of Dighipara are not as good as that of Barapukuria because it has a significant amount of more ash content in weight percentage. ${ }^{15}$

Sulfur is detrimental to environment because it can get introduced to water or air and sulfur oxides can be produced which, later on, may be the cause of acid rain and other environmental disasters. So the combustion product of coal needs to maintain sulfur content as low as possible. From the analysis of Sulfur content, the coal of Barapukuria and Dighipara has the less amount of sulfur. This percentage is very low from coal's perspective. ${ }^{16}$

The volatile materials define the amount of the products that will be released as gaseous material after coal combustion. It defines the environmental exposure of trace elements that were in the coal. A low amount of volatile material indicates less amount of combustion trace element exposure to the environment. In this work, after volatile material analysis, the volatile material of Barapukuria coals is the lowest.

The moisture content of coal indicates the wetness of the coal, which is a measurement of coal quality. According to this work, the Dighipara coals have the lowest amount of water.

The fixed carbon of coal stays as the combustion product and it is released to the environment along with trace elements is a matter of seriousness. From the result, we get an idea that the Barapukuria coals have higher fixed carbon content, whereas Dighipara has lower and Indonesia has the lowest amount of fixed carbon content.

\section{Thermo gravimetric analysis}

A thermo gravimetric analyzer was used to determine the weight loss $(\%)$ versus temperature rise for Bangladeshi coals from the two major basins- Barapukuria and Dighipara Figure 1.

The Thermo Gravimetric (TG) analyzer uses a trace amount of plain coal samples, in this case, $30.51 \mathrm{mg}$ and $27.27 \mathrm{mg}$ for Barpukuria and Dighipara respectively, and analyses the change of weight upon increasing the temperature of $10^{\circ} \mathrm{C}$ at a time.

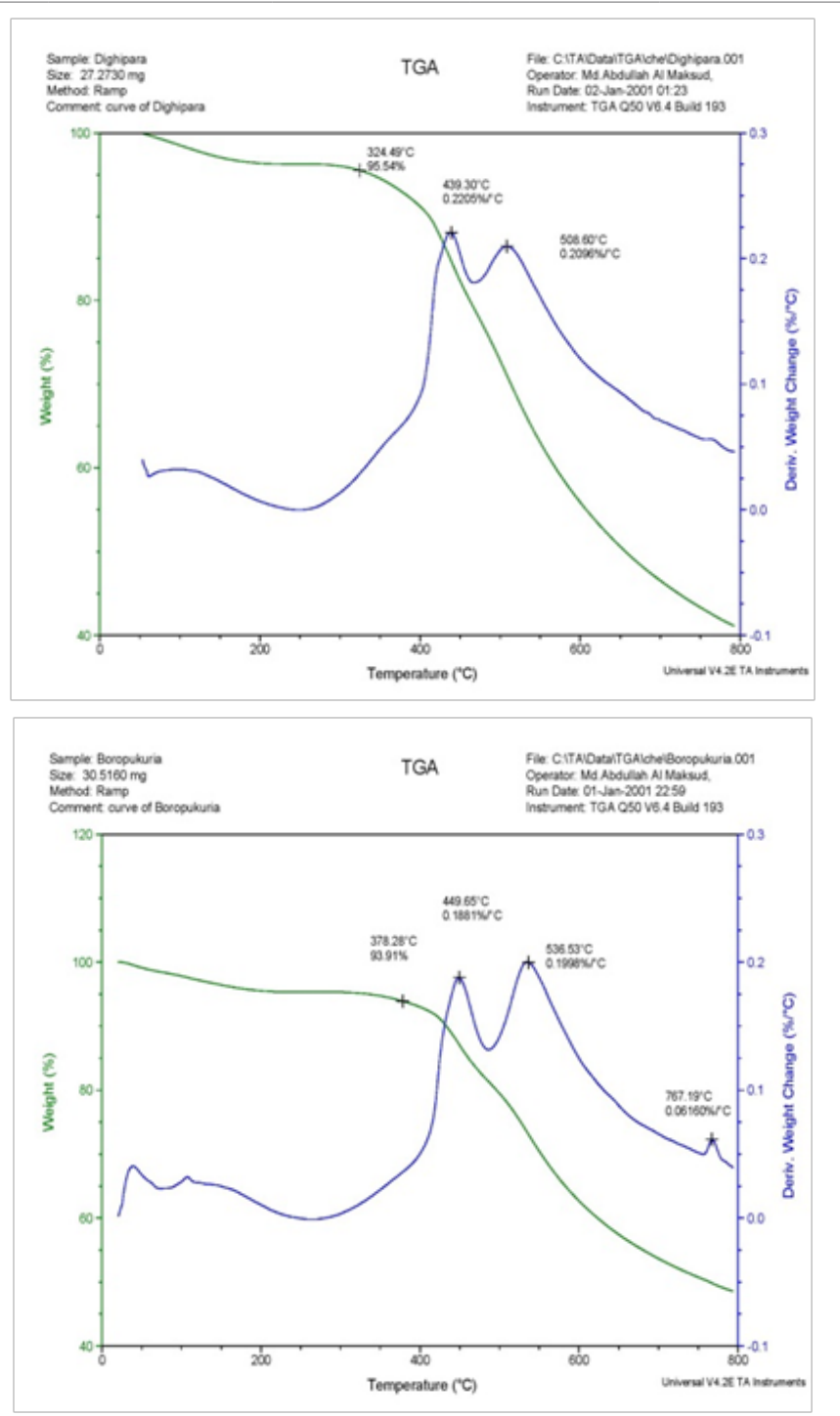

Figure I Weight (\%) /Derivative weight (\%) versus temp. chart for Barapukuria and Dighipara Coal.

In this available TG Analyzer, the temperature of the coal samples is increased from ambient temperature upto $800^{\circ} \mathrm{C}$ and plotted against the weight loss as well as derivative weight loss percentage. From the graphs it can be shown that for Barapukuria coals, weight loss dramatically increases from around $400^{\circ} \mathrm{C}$ and almost $53 \%$ of the 
initial weight is lost when $800^{\circ} \mathrm{C}$ is reached. On the other hand, for Dighipara coals, weight loss dramatically increases from around $350^{\circ} \mathrm{C}$ and almost $58 \%$ of the initial weight is lost when $800^{\circ} \mathrm{C}$ is reached. This gives away the fact that the amount of coal residues when the coal is burnt is higher for both the case of Barapukuria and Dighipara, which is also found from the proximate analysis as well. Later TG analysis of Indonesian coal was also initiated for comparison purpose Figure 2.

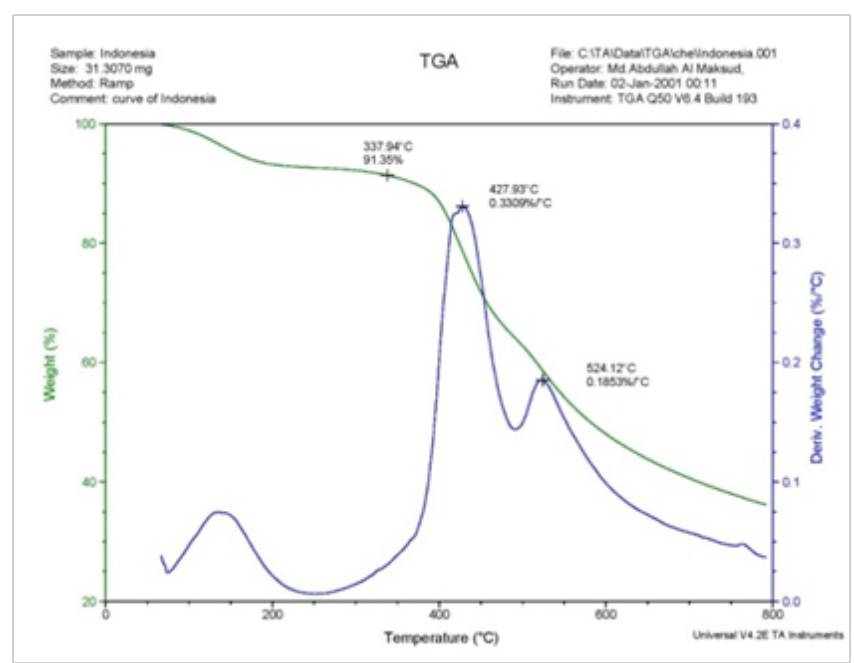

Figure 2 Weight (\%) /Derivative weight versus temperature chart for Indonesian Coal.

For Indonesian coals, weight loss increases from around $380^{\circ} \mathrm{C}$ and almost $65 \%$ of the initial weight is lost when $800^{\circ} \mathrm{C}$ is reached. It shows that the amount of final residues of Indonesian coals is lesser than Bangladeshi coals. If the residue weight is greater, the negative environmental effects of the coal by products will be easier to control, as the gaseous residues will be difficult to treat before environmental release than the solid residue.

\section{Elemental analysis (using EDS Method)}

Elemental analysis indicates the amount of trace elements in a sample. For coal, the toxic trace elements are necessary to know, so treatment can be done before release of toxic elements. The toxic elements easily mix with the soil, air, water, and in the environment which causes serious imbalance in the nature. But thorough work on trace elements of Bangladeshi coal samples is done very little.

$\mathrm{X}$-ray fluorescence is generally used to determine the trace elements in coal, but more advanced technology can be used to find out the trace elements. For that Energy Dispersive Spectroscopy analysis was done on Bangladeshi and the Indonesian coal samples.

The area-point method was used for the analysis. All of the trace elements available in that experimental region of coal sample were found. Different points from several areas of the coals were chosen for close observation.

Results shows trace amount of toxic elements such as Cadmium, Mercury, Lead, Zirconium, Selenium, Nickel etc were found in Barapukuria and Dighipara coals. The amount was very low, less than $0.5 \%$ of the total mass of samples. But the toxic elements in Indonesian coals were $9 \%$, very high compared to the Bangladeshi coals and release of these toxic elements in the environment can cause serious damage to crops, animals and also human bodies Figure 3.

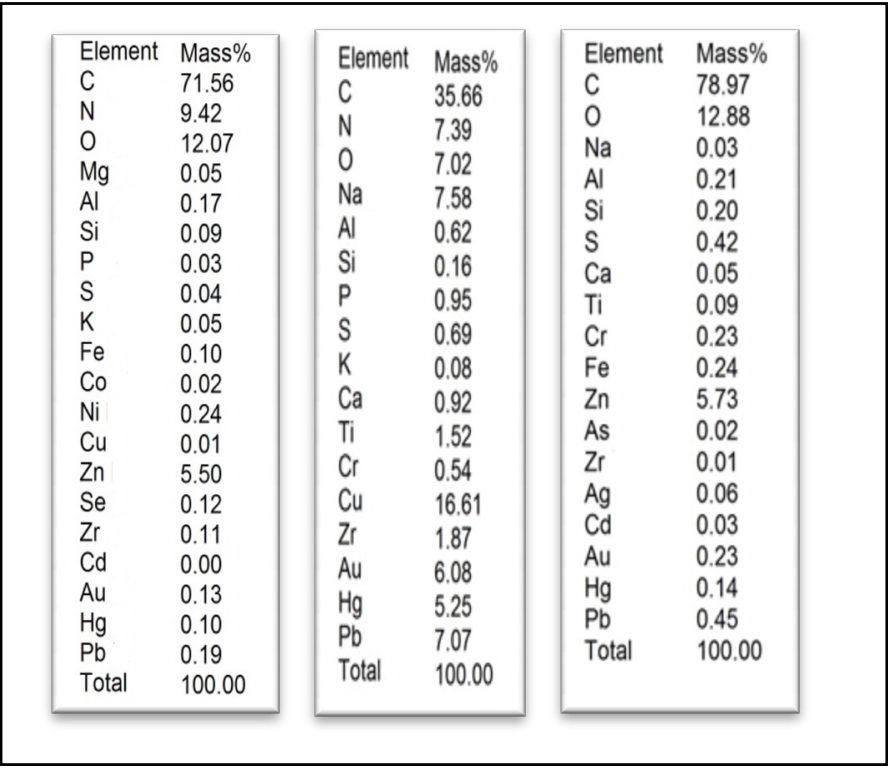

Figure 3 Elemental Analysis results of Barapukuria, Dighipara \&Indonesian Coal Samples.

\section{Conclusion}

This work was done in order to trace the accurate amount of the toxic elements that may get released in the environment when coal combustion occurs in an industry. The quality and energy efficiency of the country's finest coals were also determined to ensure that it may be used to produce more electricity to meet the high rising demand of electricity within the country, and if possible, exportation of the excess energy as well. One of the reasons of this work was to try and initiate the new works on finding out and improving the different industrial characteristics of coals in Bangladesh. In this thesis, the quality standards of the Bangladeshi coal samples were compared thoroughly with the imported commercial graded coal form Indonesia so that the quality and supreme characteristics of the country's finest Barapukuria and Dighipara coals can be easily understood. This work is undertaken so that proper care may be taken while handling and maintaining the coals. Finally more hi-tech thorough researches and investments are needed to use these coals so that these can support other fuels like natural gas and oil, as the country will soon face scarcity of the remaining fossil energy sources in near future.

\section{Acknowledgements}

None.

\section{Conflict of interest}

The author declares no conflict of interest.

\section{References}

1. Annual Book of ASTM Standards. Petroleum Products, Lubricants and Fossil Fuels. 1987. 5:5.

2. Armstrong, W (1991) Barapukuria Coal Deposits, Stage 2, Feasibility Study. Geological Survey Bangladesh-UK Coal Project. Petrobangla, Dhaka, Bangladesh, 1991.

3. Bakr A. Mining: A Case Study on the Barapukuria Coal Mining Industry, Dinajpur, Bangladesh. Journal of Energy Conversation. 2001;490-495. 
4. Bhuiyan $\mathrm{H}$, Islam $\mathrm{M}$, Ismail $\mathrm{H}$, et al. Analysis and Comparison of different coal fields and imported coal in Bangladesh. International Journal of Science, Environment and Technology. 2014;3(1):130-139.

5. Coal Chemistry and Utilization. USA: John Willy \& Sons.

6. Coal Grade and Environment in Bangladesh. International Journal of Scientific \& Engineering Research. 2013;4(4).

7. Farhaduzzaman M, Abdullah I, Aminul I. Petrographic characteristics and palaeoenvironment of the Permian coal. Journal of Asian Earth Sciences. 2002;64:272-287.

8. Farhaduzzaman M, Rahman MJJ, Rahman M. Some aspects of the geology of Phulbari Coal Basin, Dinajpur District, Northwest Bangladesh:implications for mining. Bangladesh: Proceedings of XII Geological Conference, Dhaka; 2008. 34 p.

9. Forhad H. Generation potential of Permian Gondwana Group coals and associated sediments, Barapukuria Coal Basin, Dinajpur, Bangladesh. International Research Journal of Geology and East Journal of Scientific Research. 2002;21(1):268-274.
10. J Poddar, T Hossain. Thermochim Acta. 1996;284:279.

11. J Poddar, T Hossain, Kh M Mannan. Thermochim Acta. 1995;255:211

12. J Podder, T Hossain, Kh M Mannan. An investigation into the thermal behaviour of Bangladeshi coals. Thermochimica Acta. 1995;255:221 226.

13. S Safiullah, JU Ahmad. Proceedings of Asian Seminar on Acid Rain. Taipei, China, 1993.

14. Speight JG. Handbook of Coal Analysis. USA: John Wiley and Sons: Hoboken; 2005.

15. W. Armstrong (1991) Techno-Economic Feasibility Study of Barapukuria Coal Project report, Dinajpur, Bangladesh. Annual Journal of Petrobangla. 1991.

16. Wahid H. Coal, Soil and Water Samples Collected from Barapukuria Coal Mine in Dinajpur District of Barapukuria and Dighipara basins, NW Bangladesh. Journal of Petroleum Geology. 2013. 